\title{
Expression of Plasmodium falciparum erythrocyte membrane protein $I$ in experimentally infected humans
} Thomas Lavstsen*1, Pamela Magistrado ${ }^{1}$, Cornelus C Hermsen ${ }^{3}$, Ali Salanti ${ }^{1}$, Anja TR Jensen ${ }^{1}$, Robert Sauerwein ${ }^{3}$, Lars Hviid ${ }^{2}$, Thor G Theander ${ }^{1}$ and Trine Staalsoe ${ }^{2}$

Address: ${ }^{1}$ Centre for Medical Parasitology at Institute for Medical Microbiology and Immunology, University of Copenhagen, Panum Institute 24 2, Blegdamsvej 3, 2200 Copenhagen N, Denmark, ${ }^{2}$ Centre for Medical Parasitology at Department of Infectious Diseases, Copenhagen University Hospital (Rigshospitalet), Copenhagen, Denmark and ${ }^{3}$ Radboud University Nijmegen Medical Centre, Nijmegen, The Netherlands

Email: Thomas Lavstsen* - thomaslavstsen@vip.cybercity.dk; Pamela Magistrado - pam@immi.ku.dk;

Cornelus C Hermsen - R.Hermsen@ncmls.kun.nl; Ali Salanti - hecmp@biobase.dk; Anja TR Jensen - atrj@cmp.dk;

Robert Sauerwein - R.Sauerwein@mmb.umcn.nl; Lars Hviid - lhcmp@rh.dk; Thor G Theander - theander@cmp.dk;

Trine Staalsoe - staalsoe@cmp.dk

* Corresponding author

Published: 27 April 2005

Malaria Journal 2005, 4:2I doi:I0.II86/|475-2875-4-2।
Received: 09 February 2005

Accepted: 27 April 2005

This article is available from: http://www.malariajournal.com/content/4/I/2 I

(c) 2005 Lavstsen et al; licensee BioMed Central Ltd.

This is an Open Access article distributed under the terms of the Creative Commons Attribution License (http://creativecommons.org/licenses/by/2.0), which permits unrestricted use, distribution, and reproduction in any medium, provided the original work is properly cited.

\begin{abstract}
Background: Parasites causing severe malaria in non-immune patients express a restricted subset of variant surface antigens (VSA), which are better recognized by immune sera than VSA expressed during non-severe disease in semi-immune individuals. The most prominent VSA are the var gene-encoded Plasmodium falciparum erythrocyte membrane protein I (PfEMPI) family, which is expressed on the surface of infected erythrocytes where it mediates binding to endothelial receptors. Thus, severe malaria may be caused by parasites expressing PfEMPI variants that afford parasites optimal sequestration in immunologically naïve individuals and high effective multiplication rates.

Methods: var gene transcription was analysed using real time PCR and PfEMPI expression by western blots as well as immune plasma recognition of parasite cultures established from non-immune volunteers shortly after infection with NF54 sporozoites.

Results: In cultures representing the first generation of parasites after hepatic release, all var genes were transcribed, but GroupA var genes were transcribed at the lowest levels. In cultures established from second or third generation blood stage parasites of volunteers with high in vivo parasite multiplication rates, the var gene transcription pattern differed markedly from the transcription pattern of the cultures representing first generation parasites. This indicated that parasites expressing specific var genes, mainly belonging to group $\mathrm{A}$ and $\mathrm{B}$, had expanded more effectively in vivo compared to parasites expressing other var genes. The differential expression of PfEMPI was confirmed at the protein level by immunoblot analysis. In addition, serological typing showed that immune sera more often recognized second and third generation parasites than first generation parasites.

Conclusion: In conclusion, the results presented here support the hypothesis that parasites causing severe malaria express a subset of PfEMPI, which bestows high parasite growth rates in individuals with limited pre-existing immunity.
\end{abstract}




\section{Background}

Plasmodium falciparum-encoded variant surface antigens (VSA) are expressed on the surface of infected erythrocytes (IE) and mediate binding to a range of endothelial cell receptors [1]. Endothelial adhesion contributes to the particular virulence of the P. falciparum and most likely has evolved as a mechanism to avoid parasite clearance in the spleen [2-4]. Individuals living in areas of intense parasite transmission develop immunity towards severe malaria early in life [5]. Parasites causing severe malaria in young children with limited pre-existing immunity tend to express a limited, relatively conserved subset of VSA $\left(\mathrm{VSA}_{\mathrm{SM}}\right)$ that is more often and better recognized by antibodies from most parasite-exposed individuals than the larger and more diverse $\mathrm{VSA}_{\mathrm{UM}}$ subset expressed by parasites causing uncomplicated malaria [6-8]. It thus appears that expression of $\mathrm{VSA}_{\mathrm{SM}}$ confers a selective advantage in non-immune individuals, perhaps by allowing particularly efficacious endothelial sequestration and consequently high effective growth rates. The best characterized VSA are the var gene-encoded $P$. falciparum erythrocyte membrane protein 1 (PfEMP1) family [9-11]. Each haploid parasite genome contains 50-60 var genes, of which the 59 var genes annotated in the fully sequenced $P$. falciparum clone $3 \mathrm{D} 7$ can be divided into three major groups, A, B and C, based on sequence analysis $[12,13]$. The functional relevance of this grouping is supported by the parallel differences in CD36-binding characteristics of PfEMP1 CIDR1 $\alpha$ domains. Thus, GroupA CIDR $1 \alpha$ domains do not bind CD36, whereas CIDR1 $\alpha$ domains encoded by GroupB and GroupC var genes do [14]. The 3D7 PfEMP1 repertoire may well represent the $\mathrm{VSA}_{\mathrm{UM}}$ $\mathrm{VSA}_{\mathrm{SM}}$ spectrum observed in field isolates, and recent findings point to GroupA as encoding $\mathrm{VSA}_{\mathrm{SM}}$-type PfEMP1 molecules in patient isolates [13,15-17]. Unfortunately, little is known about var gene expression in vivo, and studies have been frustrated by the difficulties in detecting and quantifying expression in parasites with unknown var gene repertoires. This difficulty has been overcome by taking advantage of the knowledge of the var gene repertoire in 3D7 and analyzing var gene expression in NF54 parasites (the parental line of 3D7) isolated from nonimmune individuals experimentally infected by mosquito challenge. Immediately upon release from the liver, the parasites appeared to transcribe all var genes, with GroupA genes being the least transcribed. However, within one or two parasite generations this pattern changed, in particular in those parasites exhibiting the fastest in vivo growth rates. Here, only a few genes dominated the var transcript population. The data indicate that PfEMP1-determined differences in growth rates shape the expressed PfEMP1 repertoire, and that some PfEMP1 variants confer high effective parasite multiplication rates in non-immune individuals.

\section{Materials and methods \\ Malaria parasites}

Parasites were isolated from Dutch volunteers exposed to mosquitoes infected with $P$. falciparum isolate NF54[18] as part of ongoing studies of experimental $P$. falciparum infections. On day 0 , ten non-immune volunteers were subjected to two or five infectious bites. Chloroquine treatment was initiated on the first day a thick smear was positive. Parasite cultures were established from 400 microlitres of packed blood cells drawn on days 8,9 , and 10 and parasites were cultured in vitro for 27 or 33 days (Figure 1) to obtain sufficient parasite material for DNA, RNA and protein analysis. The parasites were cultured in $0 \mathrm{Rh}^{+}$erythrocytes as described [19], with the addition of $2 \%$ non-immune human serum to the culture media. Long-term in vitro $3 \mathrm{D} 7$ cultures expressing $\mathrm{VSA}_{\mathrm{UM}^{-t y p e}}$ antigens or selected in vitro to express $\mathrm{VSA}_{\mathrm{SM}^{-}}$-type antigens were used as controls[20].

\section{DNA, RNA, cDNA and quantitative real-time PCR}

The development of parasitaemia was monitored by quantitative real-time PCR as described [21]. DNA, RNA and cDNA for var gene transcription analysis were prepared from synchronized parasite cultures as described [17]. Quantitative real-time PCR was performed using a Rotorgene thermal cycler system (Corbett Research, Motlake, Australia). Real-time PCR-optimized and gene-specific primers for each of all full-length var genes and a pseudogene in the 3D7 isogenic NF54 P. falciparum genome were those described in [22], except for PFI1830c. Real time primers for this gene were forward 5'ACAACAATTTCGCAAGCAAG 3', reverse 5'TTCCTCTGCCTCCTCTTCAT 3'. Standard curves for the estimation of product-related fluorescent bias and amplification efficiencies were generated for all primer pairs. For 15 primer sets, standard curves were generated both from dilution series of genomic DNA and from cloned gene fragments [17]. As the two approaches led to identical standard curves (not shown), standard curves for the remaining genes were determined from genomic DNA only. The standard curves were linear across a range of seven logs of DNA concentrations ( $R=0.9779$ to 0.9995$)$ with amplification efficiencies between 90 and 101\%. Standard curves were used for primer bias corrections in calculations of absolute transcript levels. The detection limit of the system was $\geq 20$ copies. The housekeeping genes seryl-tRNA synthetase and fructose-bisphosphate aldolase have uniform transcription profiles throughout the parasite life cycle[22], and were used as endogenous controls. Differences in var transcript distribution between samples were calculated by the $\Delta \Delta$ CT method using the endogenous controls for normalization. 

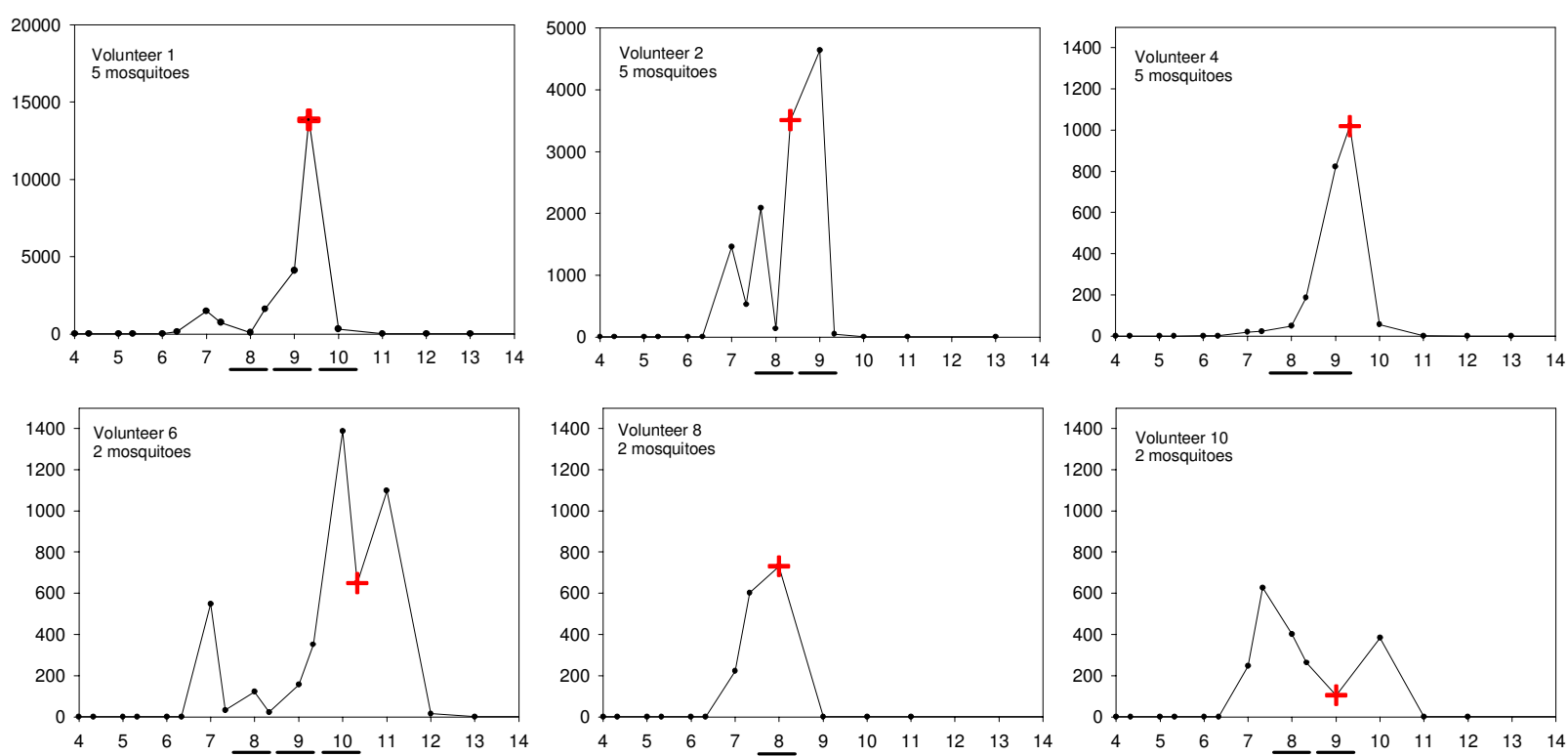

B

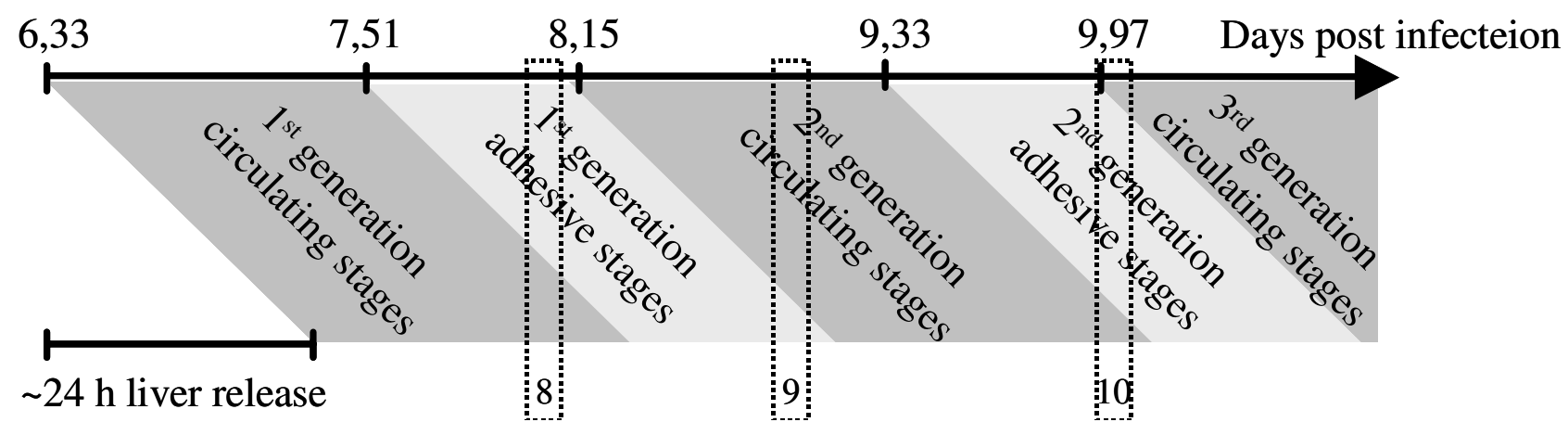

\section{Figure I}

A: Parasite densities in the six volunteers from whom parasite isolates were established. Note that parasitaemia scales are different. Closed circles indicate time points where parasite density was determined by PCR. Time points where blood samples were cultured successfully are underlined. A cross indicates time of chloroquine treatment. B: Representation of parasite generation and stage composition of a $P$. falciparum infection after liver release. Parasites were first detected on day 6,33. Estimates of parasite release from the liver ( 24 hours, over all volunteers), duration of circulating stages (I,I8 days) and adhesive stages $(0,64$ days $)$ were taken from reference 24 . Time of blood sampling is framed. When sampling blood the early circulating stages are isolated, i.e. blood drawn on day 8 predominantly contains first-generation parasites after liver release.

\section{Immunoblot analysis and flow cytometry}

Immunoblot analysis was performed as previously described [17]. Flow cytometryand plasma from malaria- exposed children and adults were used to classify the VSA expressed by parasites isolated on days 8,9 and 10 as previously described $[7,20,23]$ 


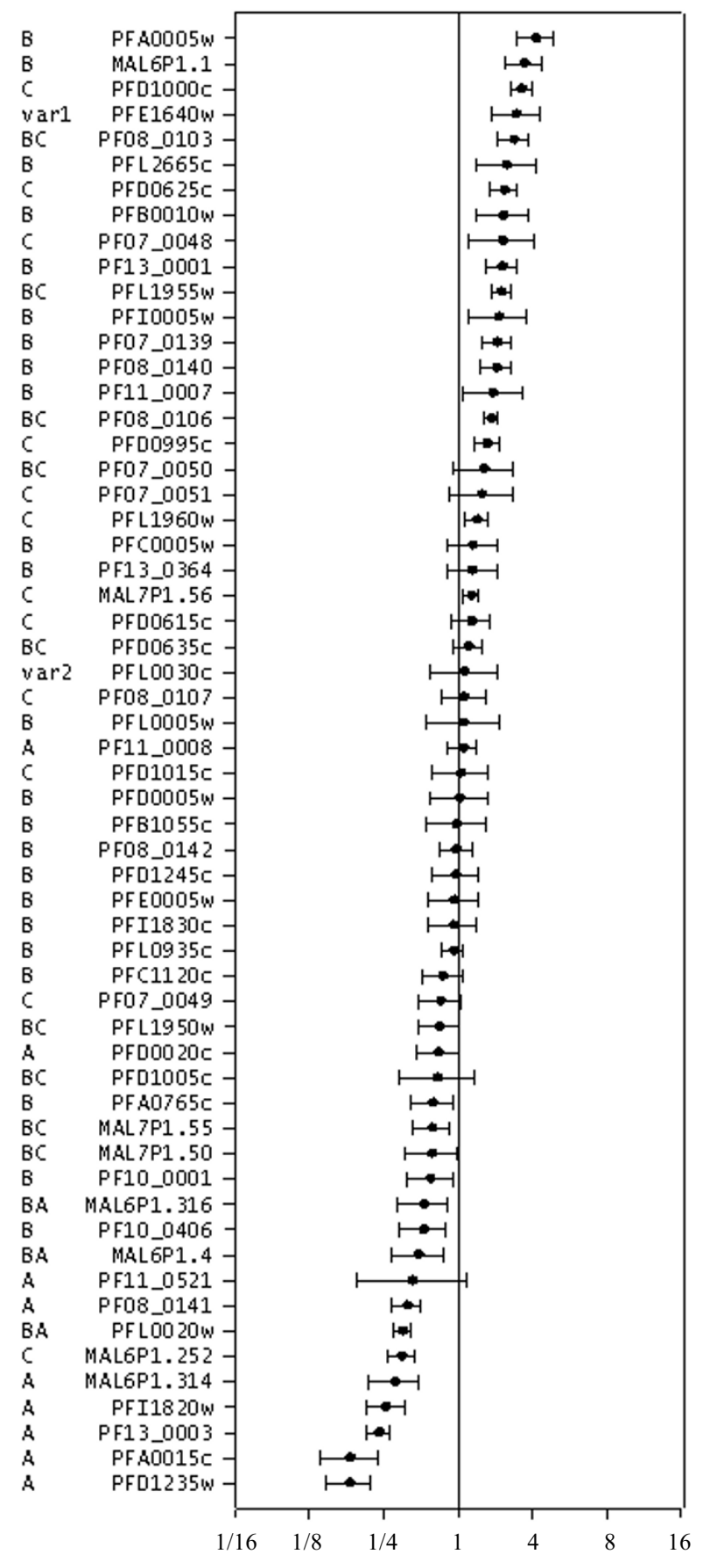

Figure 2

Var gene transcription profile of NF54 ring-stage parasite cultures established on day 8 from six volunteers. The mean transcription levels \pm I SD of primer bias-corrected and normalized values of the six cultures are shown relative to the overall mean var transcription level. Var gene name and group are indicated.

\section{Results \\ Experimental infections and establishment of parasite culture lines}

Successful infections were established in eight of the 10 volunteers. Despite low parasitaemias, a total of 13 parasite culture lines from blood collected from six of the volunteers at three time points after infection were established (Figure 1A). The highest parasite growth rates were observed in volunteers 1 and 2 with peak parasitaemias of 13,832 parasites/ml and 4,637 parasites/ml, respectively, whereas peak parasitaemias in all other volunteers were below 1,400 parasites $/ \mathrm{ml}$. As recognized from previous similar human vaccination trials [21], parasitaemias fluctuated in a distinct manner, probably reflecting liver release, sequestration of trophozoite/schizonts and release of new generations of merozoites from schizonts. Parasites obtained on day 8 were predominantly first-generation blood parasites, assuming that parasites were released from the liver between days 6,33 and 7,33[24] (Figure 1B). Similarly, day9 parasites were assumed to represent second-generation parasites, and day10 parasites a mixture of second and third generation parasites.

\section{Uniform transcription of var genes in first-generation asexual parasites}

The pattern of var gene transcription was surprisingly consistent in all the six parasite lines obtained on day8 from six of the volunteers (Figure 2). Transcripts of all var genes could be detected in ring-stage cultures, and most were transcribed at roughly similar levels. Interestingly, nine of the 10 lowest transcribed genes belonged to var subgroup $\mathrm{A}$ or $\mathrm{B} / \mathrm{A}$, which have previously been associated with severe malaria [13]. In agreement with previous studies [17] all var genes were transcribed at markedly lower levels in thetrophozoite/schizont-stage compared to ringstage parasites (data not shown). The pseudo-gene PFE1640w (var1) behaved differently and was expressed at similar levels by late stage parasites, comprising approximately $20 \%$ of the total number of var gene transcripts in trophozoite-stage parasites (data not shown).

\section{Marked changes in the var gene transcription patterns from the first to the second and third generations of asexual parasites}

The var gene transcription patterns of the five isolates obtained on day 9 and the two obtained at day 10 were different from those of the day 8 isolates, in particular in the isolates obtained from volunteers 1 and 2 in whom high parasite growth was observed (Figure 1 and 3). Ring-stage parasites from volunteer 1 showed remarkably large transcriptional changes for five var genes. Four (PF11_0008, PFD1235w, MAL6P1.1, MAL7P1.55) were transcribed at much higher (>20-fold) and one gene (PFA0015c) at markedly lower levels (12-fold) in the day10 isolate 


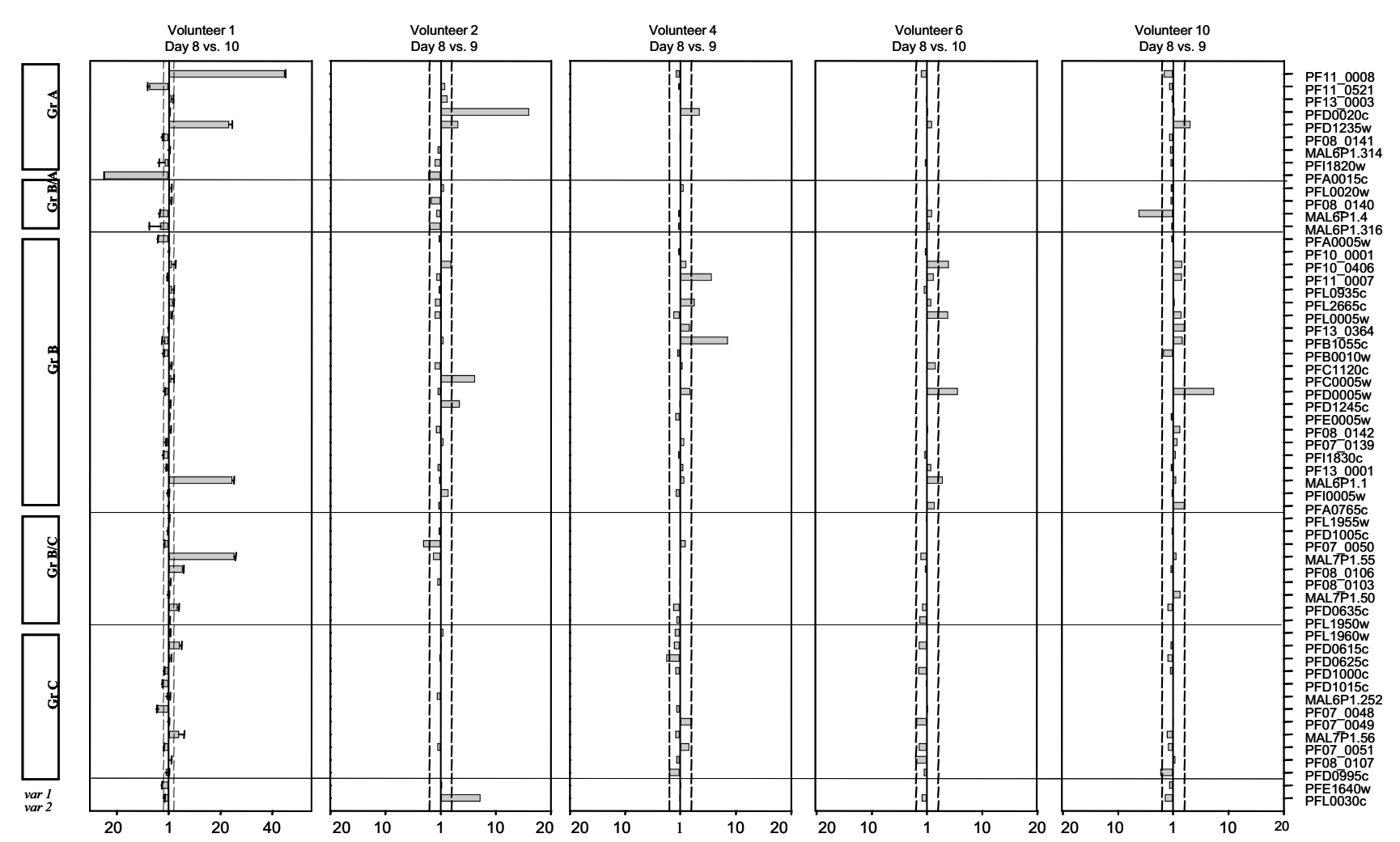

Figure 3

Fold difference in var gene transcription between NF54 ring-stage parasites isolated from the same volunteer on different days. Genes are sorted by gene groups as defined in [13]. Note that the fold-change scale for volunteer I is different from the other panels. Vertical dashed lines mark an arbitrarily defined two-fold cut off value for biologically significant changes in var gene transcription. Experiments with volunteer I were repeated three times and results are shown as means \pm SD.

compared to the day8 isolate. The estimation of absolute copy numbers (not shown) revealed that PF11_0008, MAL6P1.1 and MAL7P1.55 were the three highest transcribed var genes in the day10 isolate, comprising approximately $22 \%, 40 \%$ and $8 \%$ of all var transcripts, respectively. The abovementioned five genes also showed the most pronounced changes in gene transcription (1020 fold) when trophozoite stage parasites from days 8 and 10 were compared. The most prominent change among ring-stage parasites from volunteer 2 was the 15 -fold increased transcription of PFD0020c, which was the highest $(\sim 8 \%)$ transcribed var gene in the day 9 isolate (Figure 3 ). Only minor changes in var gene transcription patterns between days 8 and 9/10 were observed in the parasites isolated from volunteer 4, 6 and 10.

Overall, none of the var genes had a consistently altered transcript proportion in all volunteers. However, transcription of seven genes (PFD0005w, PFD0020c, PFD1235w, MAL6P1.1, PF10_0406, PF11_0007 and
PFL0005w) increased in more than one volunteer, whereas transcription of three genes (PFA0015c, MALGP1.4 and PFE1640w) decreased in more than one volunteer (Figure 3). In general, analysis of ring-stage and trophozoite/schizont-stage parasites yielded similar results.

\section{Expected changes in PfEMPI expression between first, second and third generation asexual parasites were confirmed by western blot analysis}

To investigate PfEMP1 translation in the 13 isolates, western blot analysis were performed on protein extractions of trophozoite/schizont-stage cultures using rabbit and murine antisera raised against the conserved acidic terminal segment (ATS) and against DBL5 $\delta$ of PFD1235w, respectively (Figure 4). The analysis of parasites from volunteer 1 revealed differential expression from day 8 to day10 (Figure 4A). Thus, a high molecular weight band of around $400 \mathrm{kDa}$ was seen only in the day 10 culture when using the ATS-specific antibody (Figure 4A). This band 


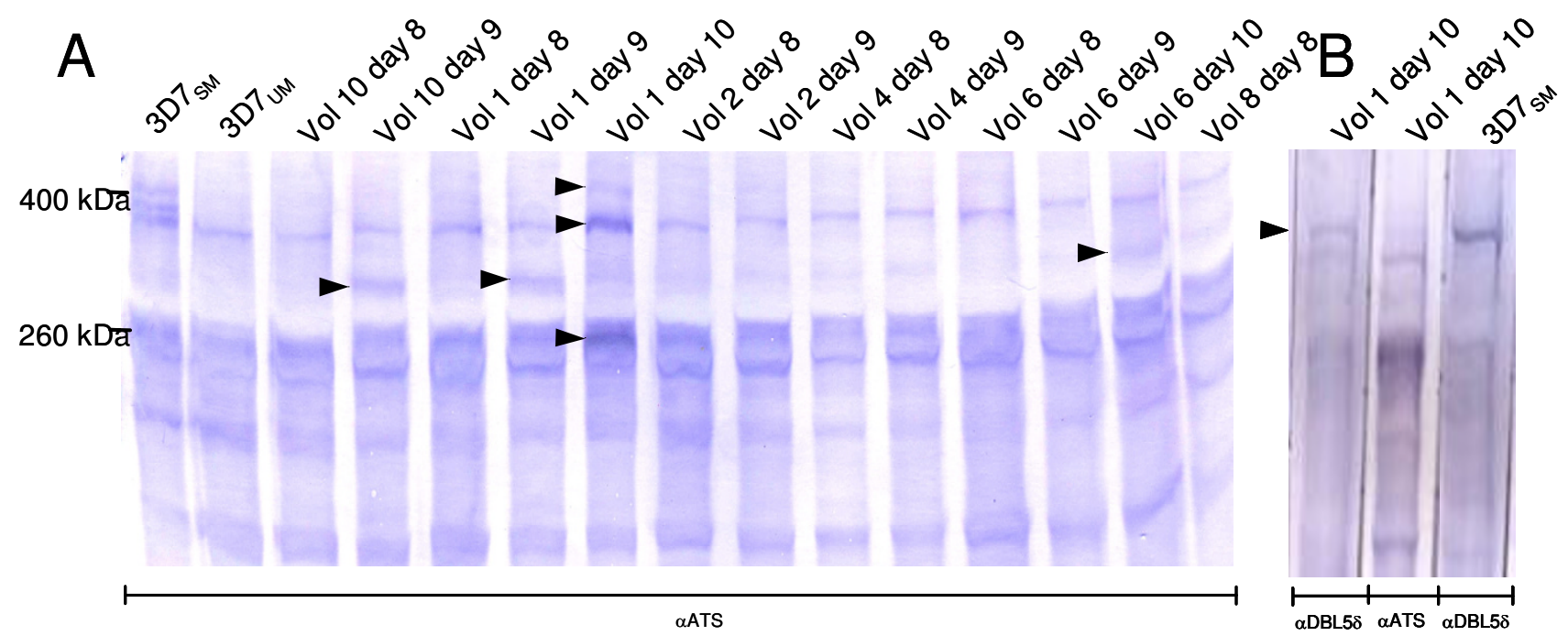

\section{Figure 4}

PfEMPI expression in trophozoite-stage cultures of unselected 3D7 (3D7 UM), 3D7 selected for expression of VSA ${ }_{S M}{ }^{-t y p e ~ I E ~}$ surface antigens $\left(3 D 7_{S M}\right)$ and of NF54 established from six volunteers on different days after infection. A: Western blot using antibodies ( $\alpha$ ATS) targeting the acidic terminal segment (ATS), which is conserved between most PfEMPI types. Black arrows indicate changes in protein expression between isolates of the same volunteer. B: Western blot identifying the $\alpha A T S-d e t e c t e d$ $400 \mathrm{kDa}$ band in the day 10 culture of volunteer I as PFDI235w/VAR4 using an $\alpha$ DBL5 $\delta$ antibody. VAR4 is expressed on the surface of the $3 \mathrm{D} 7_{S M}$ line selected for high immune serum recognition [17].

size corresponds to the expected size of PFD1235w, which also exhibited a large increase in transcription from day 8 to day 10 among parasites from this donor, and its identity was confirmed using the PFD1235w DBL5 $\delta$ antibody (Figure 4B). PFD1235w could not be detected in any of the other cultures, although small increases in transcription were found in several of the cultures (not shown). Two bands of $350 \mathrm{kDa}$ and $260 \mathrm{kDa}$ were particularly intense in the day10 culture of volunteer 1 (Figure 4A). This finding correlates with the expected sizes and elevated transcription of PF11_0008 (345 kDa), MAL6P1.1 and MAL7P1.55 (both $\sim 258 \mathrm{kDa}$ ). Transient bands at around $230 \mathrm{kDa}$ and $310 \mathrm{kDa}$ appeared to emerge on day 9 and disappear on day 10 in the cultures of volunteer 1. No obvious identity could be assigned to these proteins. In the remaining cultures, differential PfEMP1 expression detected by the ATS antibody was found in volunteers 6 and 10 . In both cases a band of $310 \mathrm{kDa}$ was observed in day10 and 9 parasites, respectively. The best candidate gene for this band is $P F D 0005 c$, which is predicted to have the observed size and was found to be more highly transcribed in the these cultures. All day 8 cultures were very similar and all appeared to dominantly express PfEMP1s around $260 \mathrm{kDa}$, which corresponds to the expected sizes of the highest transcribed genes in these cultures (figure 2).

\section{Second and third generation parasites express VSA that are recognized more frequently by immune plasma than first generation parasites}

The VSA phenotype of parasites can be classified relative to each other and in the spectrum between $V_{S S}$ and $\mathrm{VSA}_{\mathrm{UM}^{\prime}}$ depending on the proportion of individuals from an endemic area that possess antibodies to the expressed VSA $[7,20]$. To establish their VSA phenotype, the serological recognition of the isolated NF54 parasites was tested using a panel of plasma obtained from children and adults living in Coastal Ghana (Figure 5). All day 8 parasite isolates, representing the first generation of asexual blood-stage parasites, expressed VSA that were recognized by IgG in plasma samples from only a minority of the children and from about half of the adults (Figure 5). These parasites were also less well recognized than the standard 3D7 VSA $\mathrm{UM}_{\mathrm{M}}$ line, which dominantly expresses PfEMP1 encoded by GroupC var genes. The seven lines isolated on days 9 or 10 all expressed VSA that were more frequently recognized than the corresponding day8 line $(P=0.01$, Wilcoxon signed-ranked test $)$. This trend was 


\begin{tabular}{|c|c|c|c|c|c|c|c|}
\hline Volunteer & 1 & 2 & 4 & 6 & 8 & 10 & 3D7 \\
\hline Adults & & In & 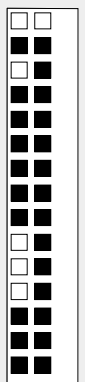 & 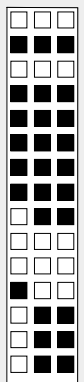 & $\begin{array}{l} \\
\square \\
\square \\
\square \\
\square \\
\square \\
\square \\
\square \\
\square \\
\square \\
\square \\
\square \\
\square\end{array}$ & 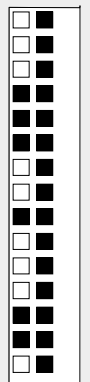 & 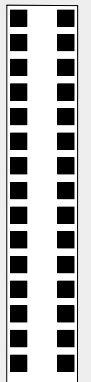 \\
\hline Children & 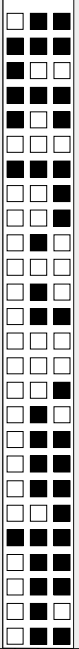 & 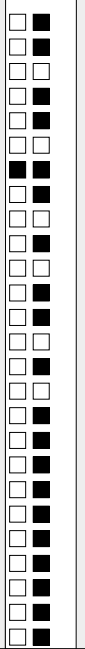 & $\begin{array}{l}\square \square \\
\square \square \\
\square \square \\
\square \square \\
\square \square \\
\square \square \\
\square \square \\
\square \square \\
\square \square \\
\square \square \\
\square \square \\
\square \square \\
\square \square \\
\square \square \\
\square \square \\
\square \square \\
\square \square \\
\square \square \\
\square \square \\
\square \square \\
\square \square \\
\square \square \\
\square \square \\
\square \square \\
\square \square \\
\square \square\end{array}$ & 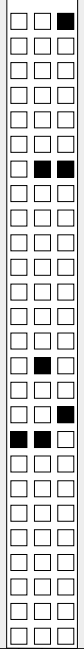 & $\begin{array}{l}\square \\
\square \\
\square \\
\square \\
\square \\
\square \\
\square \\
\square \\
\square \\
\square \\
\square \\
\square \\
\square \\
\square \\
\square \\
\square \\
\square \\
\square \\
\square \\
\square \\
\square \\
\square \\
\square \\
\square \\
\square \\
\square \\
\square\end{array}$ & 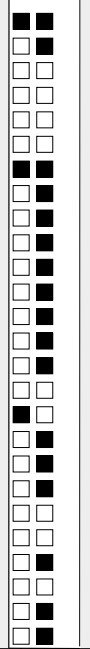 & 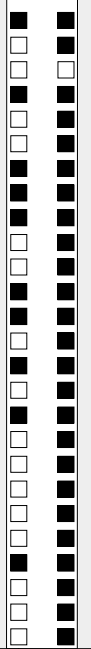 \\
\hline $\begin{array}{l}\text { Day post } \\
\text { infection }\end{array}$ & $\begin{array}{lll}89 & 10\end{array}$ & 8910 & 8910 & 8910 & 8910 & 8910 & UM SM \\
\hline
\end{tabular}

Figure 5

Plasma recognition profiles of trophozoite-stage cultures of NF54 established from six volunteers on different days after infection. Profiles of unselected 3D7 (UM) and 3D7 selected

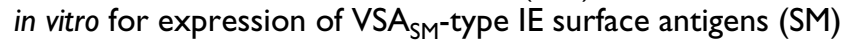
are shown for comparison. Recognition was measured by flow cytometry using IgG from Ghanaian adults and children (see Materials and Methods). Filled boxes indicate mean FITC-fluorescenceindex (MFI)abovea cut-off defined by the mean +2 standard deviations of 8 Danish control plasma.

particularly clear for the day9/10 lines from volunteers 1 , 2 and 10, which were recognized by all of the plasma samples from adults and from the majority of the children, similarly to the recognition of 3D7 selected for expression

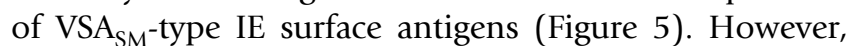
quantitatively the serum recognition of all isolates was lower than that of the $3 \mathrm{D} 7_{\mathrm{SM}}$ line (data not shown). The $3 \mathrm{D} 7 \mathrm{VSA}_{\mathrm{SM}}$ line has been selected for $\mathrm{VSA}_{\mathrm{SM}}$ expression using IgG from semi-immune children and dominantly expresses the product of PFD1235w (VAR4) on the surface on infected erythrocytes. Interestingly, parasites from volunteers 1,2 and 10 had an increased transcription of a particular var gene (PFD1235w; var4) (Figure 2) as does 3D7 in response to selection for $\mathrm{VSA}_{\mathrm{SM}}$ expression[17].

\section{Discussion}

The inter- and intra-clonal variability of the var genes have frustrated attempts to investigate the roles of the encoded PfEMP1 proteins in pathogenesis and protection. The most common strategy has been to quantify var transcription by counting the frequency of unique sequence tags, amplified by degenerate primers targeting semi-conserved blocks of DBL domains. This has been used to study phenotypically distinct laboratory lines $[10,25-29]$ and parasite strains isolated from patients with defined clinical outcomes [16,30-32] The only previous study of var gene transcription in experimentally infected humans also applied this strategy [33]. However, it requires the sequencing of a large number of clones for statistical significance and is inherently susceptible to primer bias. Together, this makes data interpretation difficult. To overcome these difficulties, sensitive and gene-specific tools were used to analyse in detail the pattern and dynamics of var gene expression in non-immune volunteers infected with a parasite with a known var gene repertoire. The necessity for in vitro expansion of parasites from blood samples with submicroscopic parasitaemias makes this approach susceptible to two separate types of bias. Firstly, cultures were established from a relatively small number of parasites and the transcription profiles of these parasites may not represent the profile of the entire in vivo population. However, in most cultures the founder population was between 100 and 4,000 parasites, and only two cultures, which did not exhibit biased transcription patterns (day 8 culture of volunteers 1 and 4) were established from less than 100 parasites. Secondly, P. falciparum has been reported to switch var gene expression at variable rates in vitro $[34,35]$. Hence, the var gene expression in the cultures at the time of transcription analysis may not reflect the expression profile in vivo at the time of blood collection. The transcription profiles of the cultures isolated on day 8 were similar and different to the profiles of the parasites isolated on days 9 and 10. This, and the fact that the differential var gene transcription, translation and serological recognition of PfEMP1 correlated with parasite growth, however, indicates that in vitro switching did not invalidate the analyses.

No var gene was dominantly transcribed in the day 8 cultures. Instead, a relatively large group of genes belonging to var groups $\mathrm{B}$ and $\mathrm{C}$ were expressed at almost similar levels and interestingly, nine of the 10 lowest transcribed genes belonged to group $\mathrm{A}$ or $\mathrm{B} / \mathrm{A}$. These data imply that the PfEMP1 expression pattern at the beginning of the infection is broad and anticipatory. In addition, the consistent increase in recognition by immune sera with time of infection and the apparent association between high 
growth rates and differential expression of a few group A and $B$ genes from first to second and third generation imply that it is the host environment that modulates the PfEMP1 expression. This is a plausible scenario because of the large and immediate differences in survival fitness that are likely to be imposed on the asexual parasites by the physiology and pre-existing immunity of the host. While most - or all - of the PfEMP1 variants that can be expressed by a given parasite will be exposed to the immune system according to this model, the majority of the variants are likely to be present too briefly to induce a significant immune response. Crucially, survival fitness differences depend on which PfEMP1 variants are being expressed and necessitate a parasite response much faster than which can be achieved by switching to advantageous var genes. Although differences in switching rates can contribute to the pattern of var gene expression [35] and may well be responsible for the differences in transcription observed on day 8 (Figure 2), differences in survival rates may be far more important in focusing and ordering PfEMP1 expression in vivo. In non-immune individuals this process would be expected to focus expression on the restricted and relatively conserved subset of VSA (VSA $\mathrm{SM}_{\mathrm{SM}}$ ) associated with severe disease in patients with little preexisting immunity $[13,17]$ It has previously been documented that in vitro selection of 3D7 for acquisition of the $\mathrm{VSA}_{\mathrm{SM}}$ phenotype is associated with expression of a subset of var genes [[15]. Strikingly, four of the five marked differentially transcribed genes (PF11_0008, PFD1235w, MAL7P1.55 and PFA0015c) in the volunteer 1 cultures, were among the few genes differentially transcribed genes upon selection for the $3 \mathrm{D} 7_{\mathrm{SM}}$ phenotype, in which there was selection for expression of PF11_0008, PFD1235w and MAL7P1.55 and against expression of PFA0015.

In the study of Peters et al [33] the clone frequency strategy was used to investigate var transcription profiles of parasites isolated from two volunteers on day 12 and 13 after infection with 3D7 by eight or nine infectious mosquito bites. One transcript, PF11_0007, belonging to var group $\mathrm{B}$, comprised half of the 39 and 41 sequences cloned from the two volunteers respectively. In total 10 and nine different var tags were found and only one belonged to var group A. The parasites were predicted to be 3rd or 4th generation and the parasitaemias in the two volunteers were 18,000 and 212,000 parasites $/ \mathrm{ml}$. Thus, these profiles are best compared with that of the day 10 isolate of volunteer 1 presented in this study. Taking into account the potential ambiguities in the interpretation of the results presented by Peters et al, we believe that the two data sets could reflect similar dynamics in the human host.

\section{Conclusion}

In conclusion, the data - in combination with earlier findings - suggest that PfEMP1 expression is determined and ordered mainly by host physiology and immunity, and that this will cause infections in non-immune individuals to be dominated by $\mathrm{VSA}_{\mathrm{SM}^{-}}$-type variants such as those encoded by Group A and B var genes.

\section{Abbreviations}

PfEMP1 Plasmodium falciparum erythrocyte membrane protein 1

VSA $_{U M}$ variant surface antigens associated with uncomplicated malaria

VSA $_{S M}$ variant surface antigens associated with severe malaria

\section{Authors' contributions}

TL carried out the transcription analysis, took part in the parasite sampling and culturing and prepared the manuscript. PM performed the western blot analysis. $\mathrm{CCH}$ ran the human vaccination trials. TS managed the sample collection, culturing of parasites as well as performed and the flow cytometry analysis. TL, CCH, TGT and TS conceived the design of the study. All authors helped to draft and approved the final manuscript.

\section{Acknowledgements}

We thank Liselotte Wolters for performing QRT-PCR and Petra Schneider and the team at Clinical Center for Malaria Studies, University Medical Center Nijmegen, The Netherlands for sampling parasites from volunteers. Maiken Christensen and Kirsten Pihl are thanked for excellent technical assistance. The PlasmoDB database http://www.plasmodb.org has been a valuable resource for this work and the database developers and researchers who have made their data available here are thanked. The study received financial support from The Danish Medical Research Council (SSVF grant no. 63686), and the Commission of the European Communities (grant no. QLK2-CT-2002-01 197, EUROMALVAC). PM and AS are supported by the Gates Malaria Partnership Ph.D. scholarships.

\section{References}

I. Kyes S, Horrocks P, Newbold C: Antigenic variation at the infected red cell surface in malaria. Annu Rev Microbiol 200I, 55:673-707.

2. David PH, Hommel M, Miller LH, Udeinya IJ, Oligino LD: Parasite sequestration in Plasmodium falciparum malaria: spleen and antibody modulation of cytoadherence of infected erythrocytes. Proc Natl Acad Sci U S A 1983, 80:5075-5079.

3. Howard RJ, Barnwell JW: Roles of surface antigens on malariainfected red blood cells in evasion of immunity. Contemp Top Immunobiol | 984, | 2: |27-19|.

4. Berendt AR, Ferguson DJP, Newbold Cl: Sequestration in Plasmodium falciparum malaria: sticky cells and sticky problems. Parasitol Today 1990, 6:247-254.

5. Gupta S, Snow RW, Donnelly CA, Marsh K, Newbold C: Immunity to non-cerebral severe malaria is acquired after one or two infections. Nature Med 1999, 5:340-343.

6. Bull PC, Kortok M, Kai O, Ndungu F, Ross A, Lowe BS, Newbold Cl, Marsh K: Plasmodium falciparum -infected erythrocytes: agglutination by diverse Kenyan plasma is associated with severe disease and young host age. J Infect Dis 2000, 182:252-259. 
7. Nielsen M, Staalsoe T, Kurtzhals J, Goka B, Dodoo D, Alifrangis M, Theander TG, Akanmori BD, Hviid L: Plasmodium falciparum variant surface antigen expression varies between isolates causing severe and non-severe malaria and is modified by acquired immunity. J Immunol 2002, 168:3444-3450.

8. Nielsen MA, Vestergaard LS, Lusingu J, Kurtzhals JA, Giha HA, Grevstad B, Goka BQ, Lemnge MM, Jensen JB, Akanmori BD, Theander TG, Staalsoe T, Hviid L: Geographical and temporal conservation of antibody recognition of Plasmodium falciparum variant surface antigens. Infect Immun 2004, 72:353 I-3535.

9. Baruch D, Pasloske BL, Singh H, Bi X, Ma X, Feldman M, Taraschi TF, Howard Rl: Cloning the $P$. falciparum gene encoding PfEMPI, a malarial variant antigen and adherence receptor on the surface of parasitized human erythrocytes. Cell 1995, 82:77-87.

10. Smith J, Chitnis C, Craig A, Roberts D, Hudson-Taylor D, Peterson $D$, Pinches R, Newbold Cl, Miller LH: Switches in expression of Plasmodium falciparum var genes correlate with changes in antigenic and cytoadherent phenotypes of infected erythrocytes. Cell 1995, 82:10I-II0.

II. Su X, Heatwole V, Wertheimer S, Guinet F, Herrfeldt J, Peterson D, Ravetch JA, Wellems TE: The large diverse gene family var encodes proteins involved in cytoadherence and antigenic variation of Plasmodium falciparum -infected erythrocytes. Cell 1995, 82:89-100.

12. Gardner MJ, Hall N, Fung E, White O, Berriman M, Hyman RW, Carlton JM, Pain A, Nelson KE, Bowman S, Paulsen IT, James K, Eisen JA, Rutherford K, Salzberg SL, Craig A, Kyes S, Chan MS, Nene V, Shallom SJ, Suh B, Peterson J, Angiuoli S, Pertea M, Allen J, Selengut J, Haft $D$, Mather MW, Vaidya AB, Martin DM, Fairlamb AH, Fraunholz MJ, Roos DS, Ralph SA, McFadden GI, Cummings LM, Subramanian GM, Mungall C, Venter JC, Carucci DJ, Hoffman SL, Newbold C, Davis RW, Fraser CM, Barrell B: Genome sequence of the human malaria parasite Plasmodium falciparum. Nature 2002, 4|9:498-5II.

13. Lavstsen T, Salanti A, Jensen ATR, Arnot DE, Theander TG: Subgrouping of Plasmodium falciparum 3D7 var genes based on sequence analysis of coding and non-coding regions. Malar J 2003, 2:27.

14. Robinson BA, Welch TL, Smith JD: Widespread functional specialization of Plasmodium falciparum erythrocyte membrane protein I family members to bind CD36 analysed across a parasite genome. Mol Microbiol 2003, 47:1265-1278.

15. Bian Z, Wang G, Tian X, Fan J: Expression of Plasmodium falciparum -infected erythrocyte membrane protein from cerebral malaria patients. Zhongguo ji Sheng Chong Xue Yu Ji Sheng Chong Bing Za Zhi 1999, 17:359-362.

16. Kirchgatter K, Portillo HA: Association of severe noncerebral Plasmodium falciparum malaria in Brazil with expressed PfEMPI DBLI alpha sequences lacking cysteine residues. Mol Med 2002, 8(I): 16-23.

17. Jensen AT, Magistrado P, Sharp S, Joergensen L, Lavstsen T, Chiucchiuini A, Salanti A, Vestergaard LS, Lusingu JP, Hermsen R, Sauerwein R, Christensen J, Nielsen MA, Hviid L, Sutherland C, Staalsoe T, Theander TG: Plasmodium falciparum associated with severe childhood malaria preferentially expresses PfEMPI encoded by group A var genes. J Exp Med 2004, 199: I 179-1 I 90.

18. Delemarre BJ, Van der Kaay HJ: Malaria tropica op natuurlijke wijze verkregen in Nederland. Ned Tijdschr Geneeskd 1979, | 23: | $98|-| 982$.

19. Cranmer SL, Magowan C, Liang J, Coppel RL, Cooke BM: An alternative to serum for cultivation of Plasmodium falciparum in vitro. Trans R Soc Trop Med Hyg 1997, 91 1:363-365.

20. Staalsoe T, Nielsen MA, Vestergaard LS, Jensen AT, Theander TG, Hviid L: In vitro selection of Plasmodium falciparum 3D7 for expression of variant surface antigens associated with severe malaria in African children. Parasite Immunol 2003, 25:42I-427.

21. Hermsen CC, Telgt DS, Linders EH, van de Locht LA, Eling WM, Mensink EJ, Sauerwein RW: Detection of Plasmodium falciparum malaria parasites in vivo by real-time quantitative PCR. Mol Biochem Parasitol 200I, I I 8:247-25I.

22. Salanti A, Staalsoe T, Lavstsen T, Jensen A, Sowa M, Arnot D, Hviid L, Theander TG: Selective upregulation of a single distinctly structured var gene in chondroitin sulphate A-adhering Plasmodium falciparum involved in pregnancy-associated malaria. Molecular Microbiology 2003, 49: I79-191 I.
23. Staalsoe T, Giha HA, Dodoo D, Theander TG, Hviid L: Detection of antibodies to variant antigens on Plasmodium falciparum infected erythrocytes by flow cytometry. Cytometry 1999, 35:329-336.

24. Hermsen CC, de Vlas SJ, Van Gemert GJ, Telgt DS, Verhage DF, Sauerwein RW: Testing vaccines in human experimental malaria: statistical analysis of parasitaemia measured by a quantitative real-time polymerase chain reaction. Am J Trop Med Hyg 2004, 7I: |96-20|

25. Taylor HM, Kyes SA, Harris D, Kriek N, Newbold Cl: A study of var gene transcription in vitro using universal var gene primers. Mol Biochem Parasitol 2000, 105:13-23.

26. Noviyanti R, Brown GV, Wickham ME, Duffy MF, Cowman AF, Reeder JC: Multiple var gene transcripts are expressed in Plasmodium falciparum infected erythrocytes selected for adhesion. Mol Biochem Parasitol 200 I, I I 4:227-237.

27. Duffy MF, Brown GV, Basuki W, Krejany EO, Noviyanti R, Cowman AF, Reeder JC: Transcription of multiple var genes by individual, trophozoite-stage Plasmodium falciparum cells expressing a chondroitin sulphate $\mathbf{A}$ binding phenotype. Mol Microbiol 2002, 43: I $285-1293$.

28. Fernandez V, Chen Q, Sundstrom A, Scherf A, Hagblom P, Wahlgren $\mathrm{M}$ : Mosaic-like transcription of var genes in single Plasmodium falciparum parasites. Mol Biochem Parasitol 2002, I21:195-203.

29. Winter G, Chen Q, Flick K, Kremsner P, Fernandez V, Wahlgren M: The 3D7var5.2 (var COMMON) type var gene family is commonly expressed in non-placental Plasmodium falciparum malaria. Mol Biochem Parasitol 2003, I 27: I79-I9I.

30. Afonso NP, Wunderlich G, Shugiro TM, d'Arc Neves CJ, Jose MM, Scherf A, Pereira-da-Silva LH: Plasmodium falciparum : analysis of transcribed var gene sequences in natural isolates from the Brazilian Amazon region. Exp Parasitol 2002, I0 I: I I I-120.

31. Fried M, Duffy PE: Two DBLgamma subtypes are commonly expressed by placental isolates of Plasmodium falciparum. Mol Biochem Parasitol 2002, I 22:20I-2I0.

32. Kaestli M, Cortes A, Lagog M, Ott M, Beck HP: Longitudinal assessment of Plasmodium falciparum var gene transcription in naturally infected asymptomatic children in Papua New Guinea. J Infect Dis 2004, 189:1942-1951.

33. Peters J, Fowler E, Gatton M, Chen N, Saul A, Cheng Q: High diversity and rapid changeover of expressed var genes during the acute phase of Plasmodium falciparum infections in human volunteers. Proc Natl Acad Sci U S A 2002, 99: 10689-10694.

34. Roberts DJ, Craig AG, Berendt AR, Pinches R, Nash G, Marsh K, Newbold Cl: Rapid switching to multiple antigenic and adhesive phenotypes in malaria. Nature 1992, 357:689-692.

35. Horrocks P, Pinches R, Christodoulou Z, Kyes SA, Newbold Cl: Variable var transition rates underlie antigenic variation in malaria. Proc Natl Acad Sci U S A 2004, I 0 I: I I I29-1 I I 34.

Publish with Bio Med Central and every scientist can read your work free of charge

"BioMed Central will be the most significant development for disseminating the results of biomedical research in our lifetime. "

Sir Paul Nurse, Cancer Research UK

Your research papers will be:

- available free of charge to the entire biomedical community

- peer reviewed and published immediately upon acceptance

- cited in PubMed and archived on PubMed Central

- yours - you keep the copyright 